\title{
Molecular abnormalities of collagen
}

\author{
F. M. POPE AND A. C. NICHOLLS \\ From the Clinical Research Centre, Northwick Park Hospital, Harrow, Middlesex
}

Others have described the structure and synthesis of collagen and the techniques of collagen analysis (D. S. Jackson (Jackson, 1978) at page 44 and A. J. Bailey (Bailey, 1978) at page 49. Collectively these techniques have already increased the molecular understanding of both the inherited and acquired collagan defects. We shall discuss here the question of heredity and collagen abnormalities.

\section{Inherited diseases of collagen}

Many inherited abnormalities of collagen are likely and may be listed under the following headings as proved, probable, or possible.

Proved Ehlers-Danlos syndrome (EDS) (types III, IV, V, VI, VII); osteogenesis imperfecta (broadboned type); thanatophoric dwarfism; dermatosparaxis (animal equivalent of EDS VII); blotchy mice (animal equivalent of EDS $\mathrm{V}$ ).

Probable Marfan syndrome; pseudoxanthoma elasticum (some types); epidermolysis bullosa (some types).

Possible Progeria; Werner's syndrome; neurofibromatosis; mongolism.

Known defects have affected either collagen crosslinking or production of types I and III. Basement membrane defects await identification. Molecular abnormalities of collagen have been convincingly shown in several types of Ehlers-Danlos syndrome.

\section{EHLERS-DANLOS SYNDROME}

This disorder has proved to be as heterogeneous biochemically as it is clinically (Table). Originally considered one disease (Ehlers, 1901; Johnson and Falls, 1949), two (McKusick, 1959), three (Barabas, 1967), five (Barabas, 1967), and then seven abnormalities (Lichtenstein et al., 1974; Pinnell et al., 1972) have been recognised. Even this classification is incomplete and we have recently studied a probable eighth clinical type (Pope, 1977). EDS type IV is thought to represent at least two disorders and EDS type III may also be heterogeneous. Eight types of procollagen peptidase deficiency (EDS VII) are theoretically possible. Anomalous steps in the collagen biosynthetic pathway have been identified. Failed synthesis of complete chains (Pope et al., 1975), cross-linking abnormalities (Pinnell et al., 1972; Lichtenstein et al., 1974; DiFerrante et al., 1975). mishydroxylation of hydroxylysine (Pinnell et al., 1972), procollagen cleavage impairment (Lichtenstein et al., 1974), and alteration in collagen ratios have all been described (Pope et al., 1975; Penttinen et al., 1975; Sykes et al., 1977). Doubtless other defects await identification.

EDS TYPE I (GRAVIS)

Hyperextensible skin, loose jointedness, facial scarring (typically under the chin), epicanthic folds, blue sclerae, paper-tissue scars, bruising, pectus excavatum, and soft, smooth, easily torn skin are the typical features of this disorder (Fig. 1) (Beighton, 1970). It is the classical form of the syndrome typical of the early descriptions of EDS. Aortic incompetence and aortic rupture are rare but mitral valve prolapse is not. Inheritance is as an autosomal dominant but the precise biochemical

Table Classification of Ehlers-Danlos syndrome (EDS)

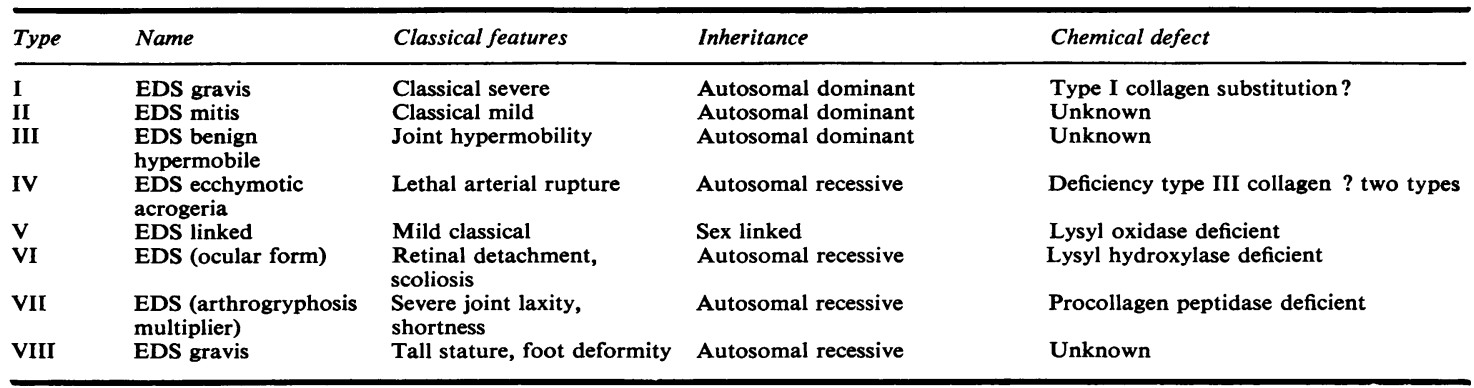




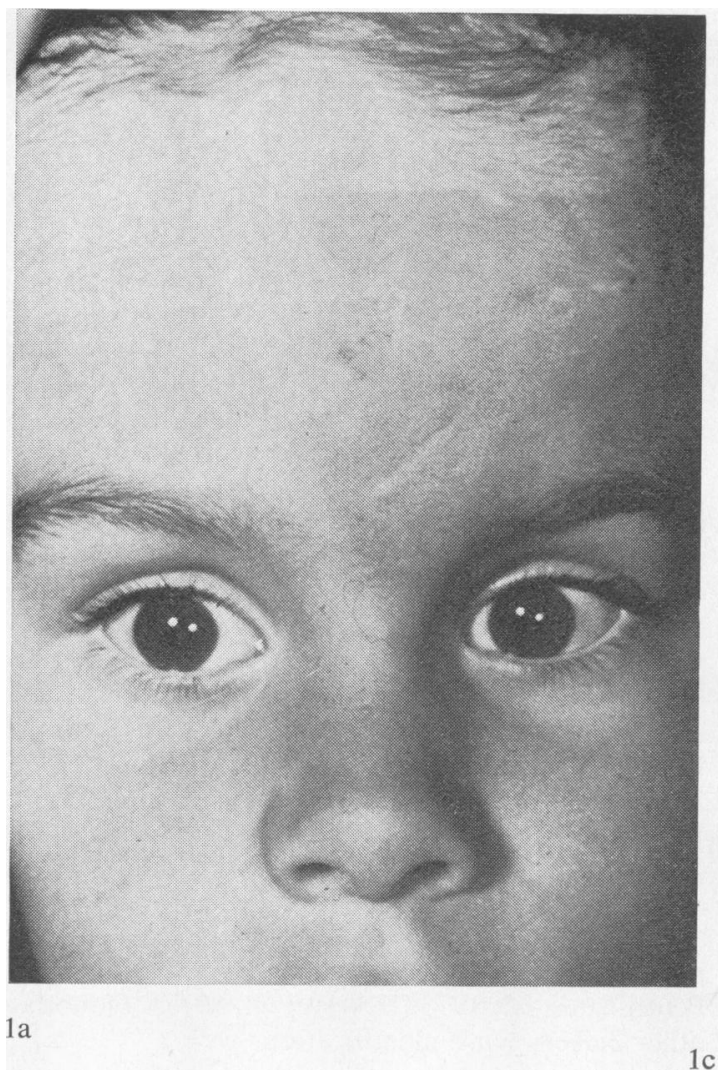

Fig. 1 Typical EDS type I showing (a) scarred forehead, (b) papyraceous scarring of knees, (c) loose jointedness. defect is unidentified. Collagen cross-linking may be faulty and increased solubility of tissue collagens has been provisionally described. Amino-acid substitutions are suspected (Steinmann et al., 1977).

EDS TYPE II (MITIS)

Scarring is less severe (Beighton, 1970), but bruising is especially common. Skin is hyperextensible and there is limited hypermobility. Inheritance is as an autosomal dominant. The basic defect is unidentified. Prognosis is good.

\section{EDS TYPE III}

Scarring is slight, but loose-jointedness is especially obvious (Beighton, 1970). The skin is usually soft and hyperextensible. Early osteoarthrosis and spontaneous dislocation of large joints is common. This group may be heterogeneous and is probably the commonest variety of EDS. Inheritance is as an autosomal dominant.
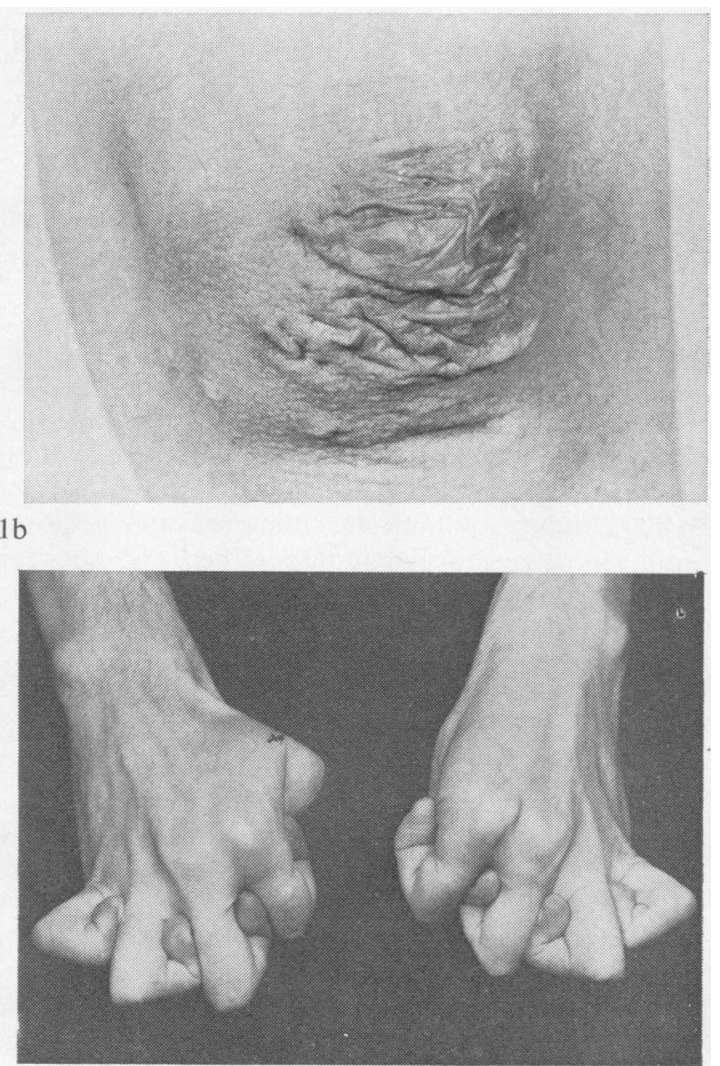

EDS TYPE IV

This especially interesting autosomal recessive defect (Fig. 2) has been given different names in various clinical specialties and regarded as distinct entities by each.

European dermatologists first described EDS IV as a premature ageing defect, acrogeria (Gottron, 1941; Basex and Dupré, 1955). The Textbook of Dermatology (1972) categorically separates it from EDS. Then Barabas (1967) and later Beighton (1970) recognised the heterogeneity of EDS and described the dangerous ecchymotic or arterial type which McKusick (1972) later called EDS IV. Beighton and McKusicks' illustrations are identical with those of the patients described as acrogeric. McKusick now acknowledges them to be one and the same (McKusick, 1975).

We have studied several affected patients and there has been a complete lack of type III collagen in tissues and cultured skin fibroblasts from most of 


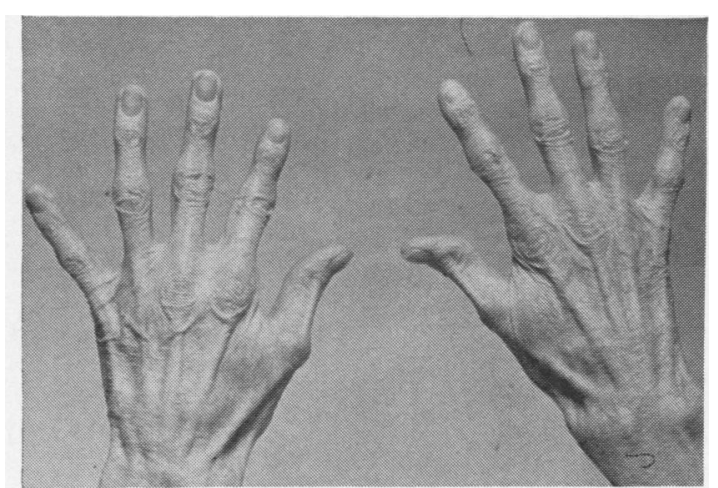

$2 \mathrm{a}$

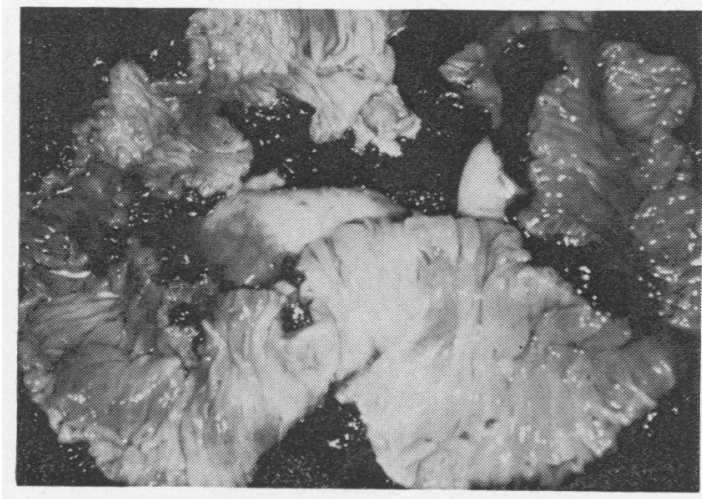

$2 \mathrm{~b}$

Fig. 2 EDS type IV. (a) Prematurely aged hands (acrogeria). (b) Intestinal haemorrhage.

them (Fig. 3) (Pope et al., 1975). Obligate heterozygote parents showed intermediate levels of type III collagens (which we estimated at $30 \%$ type III in tissues) (Pope et al., 1977). The failure to produce an essential structural protein with intermediate levels in parents is closely analogous to the thalassaemias. Variations in haemoglobin production from zero to several percent can result from gene deletion and faulty control of synthetic rate (leaky mutants) (Williamson, 1977; Benz and Nathan, 1975). Small amounts of type III collagen appear to be produced by some patients who survive longer than usual. Martin and his colleagues have some evidence that this is true in tissue culture (Martin and Steinmann, 1977) and we have patients of this type whose tissues seem to contain small amounts of type III peptides (Fig. 3e).
EDS TYPE V (LYSYL OXIDASE DEFICIENCY)

This is inherited as a sex-linked recessive trait (affected sons with carrier mothers). DiFerrante et al. (1975) showed that lysyl oxidase (involved in cross-linking) is deficient in the skin fibroblasts. The features are those of classical EDS but scarring is less severe. The disorder is benign in humans, but oxidase-deficient, blotchy mice often die from spontaneous aortic rupture (Rowe et al., 1974). Lysyl oxidase is probably polymorphic so that different tissue-specific mutations have widely disparate effects. Close analogies to the mouse model may therefore be expected in humans.

EDS TYPE VI (HYDROXYLYSINE DEFICIENCY) This variant was the first molecular defect of collagen to be identified. Retinal detachment, severe kyphoscoliosis (Fig. 4), and premature aortic rupture complicate the usual clinical signs of EDS (McKusick, 1972). Pinnell and colleagues (1972) detected hydroxylysine deficiency in skin biopsies from such patients and Sussman et al. (1974) confirmed that a lysyl hydrosylase defect is responsible for the deficiency. The enzyme hydroxylates lysine residues in the collagen chain after its ribosomal translation. In the face of the defect faulty or unusual cross-linking presumably results. Alternatively, adequate cross-links occur between the non-hydroxylated lysines and impaired glycosylation explains the various clinical signs.

\section{EDS TYPE VII (PROCOLLAGEN PEPTIDASE DEFICIENCY)}

This variety has extreme joint laxity and short stature in addition to the usual features of EDS. Lichtenstein et al. (1974) showed that tissues from such patients contained only procollagen, the precursor of collagen (Fig. 5). This fault follows deficiency of procollagen peptidase, the enzyme responsible for removing the extension peptides and the conversion of procollagen to collagen. The effect of procollagen persistence is to interfere with fibril formation. In sheep and cattle this is lethal (Helle and Nes, 1972; Lenaers et al., 1971). In man the defect is relatively benign. Possibly different peptidases act upon amino and carboxy terminal extensions of each particular collagen type. Eight separate abnormalities are theoretically possible, one for every two extensions of the four collagen types. This may explain the difference between the human and animal disorders.

\section{EDS TYPE VIII}

We have recently investigated an EDS patient with additonal tall stature and orthopaedic defects but otherwise indistinguishable from EDS I. Inheritance appears to be as an autosomal recessive characteris- 


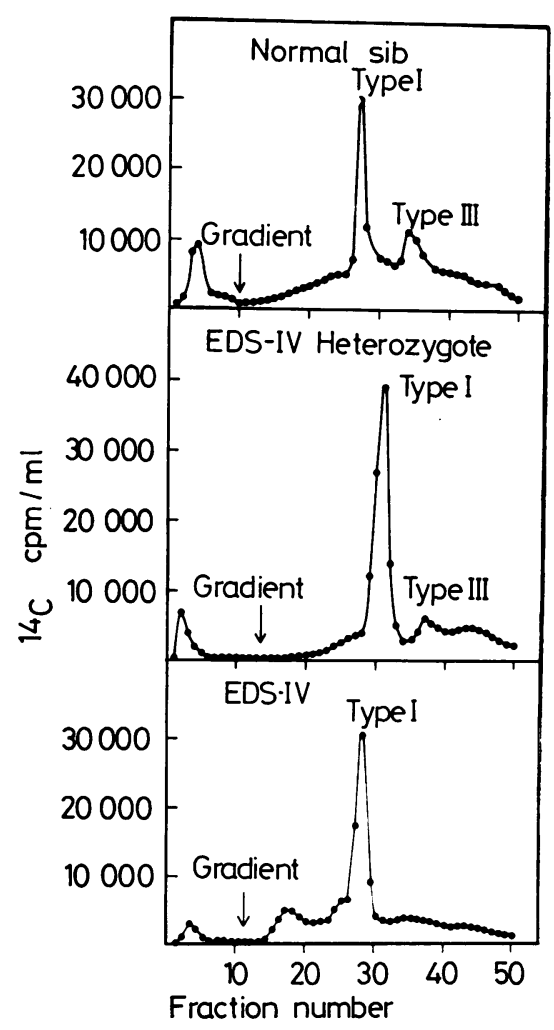

$3 a$

tic in this case. Work is in progress to identify the molecular abnormality.

\section{OSTEOGENESIS IMPERFECTA（OI）}

Autosomal dominant and recessive variants of this defect are likely and genetic heterogeneity probable for each (McKusick, 1972; Pope, 1976). The disease (Fig. 6) can vary from very mild, with few fractures, to extremely severe. In the latter slight damage from coughing or sudden movement are sufficient to fracture bones. Overlap with the Eh!ers-Danlos syndrome occurs and we have recently seen a 21year-old woman with pronounced joint laxity combined with otherwise typical, mild OI. Severe patterns of disease occur in which there is enlargement of the head, prominent blue sclerae, and dwarfism with soft silky skin and mild loosejointedness. Radiographs show general osteoporosis with delicate, twisted bones. Parents of such individuals have the general features of inherited connective tissue diseases with bruising, hyperextensible skin, and loose-jointedness. If such individuals can be identified as heterozygotes a very real advance will

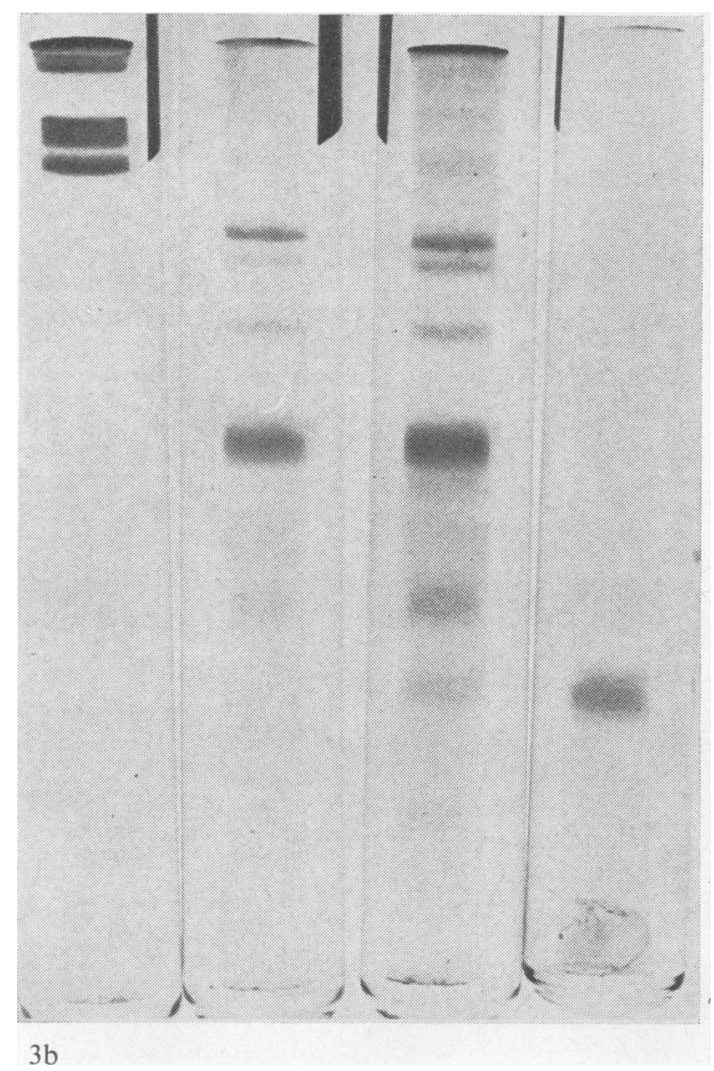

be possible in the genetic counselling of this $\mathrm{OI}$ variant. Penttinen et al. (1975) advanced the molecular understanding of OI when they showed that cultured skin fibroblasts from the lethal, broadboned variety synthesised reduced amounts of type I collagen. The distribution of collagens in tissues was not fully investigated. Inheritance of this lethal variant is probably as an autosomal recessive characteristic, although autosomal dominance and genetic heterogeneity are possible.

Even more heterogeneity of OI is likely. Sykes et al. (1977) have suggested that the measurement of type I: III collagen ratios may help to identify such defects. Levin et al. (1978) claim that tooth pattern can be used to separate OI phenotypes and that dentinogenesis imperfecta breeds true within OI families. Different collagen patterns can be expected in such situations.

\section{Collagen defects waiting identification}

MARFAN SYNDROME

Tall stature, arachnodactyly, long extremities, dis- 


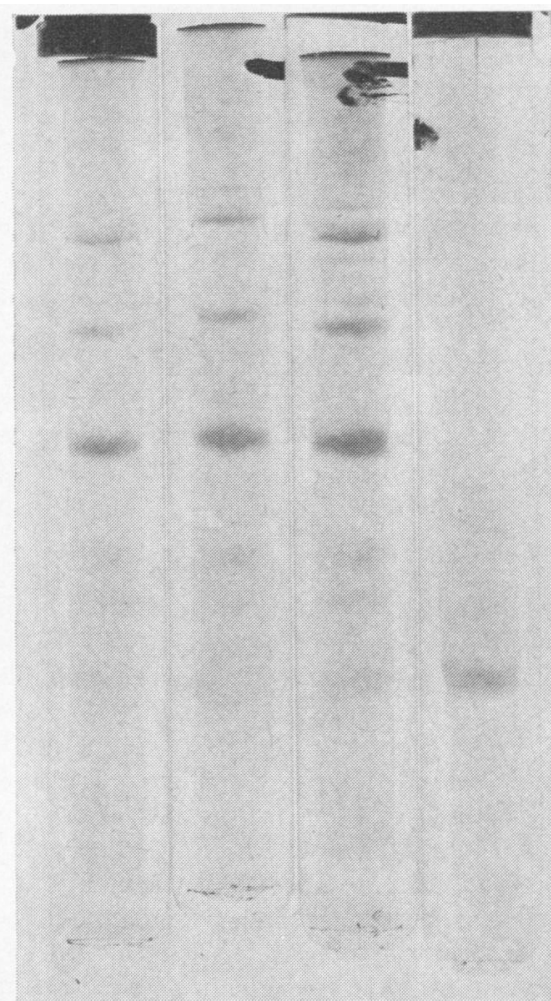

$3 \mathrm{c}$

Fig. 3 (a) Procollagen patterns of homozygous normal, abnormal, and heterozygotes as produced by $D E A E$ chromatography of labelled cultured human fibroblasts (by permission of Journal of Medical Genetics). (b) Cyanogen bromide patterns of, from left, uncleaved collagen, EDS IV skin, normal skin, and $\alpha I$ (III) CB8. (c) Cyanogen bromide patterns of EDS IV heterozygote skin of, from left, normal, twice normal, and thrice normal concentration. The fourth gel is $\alpha 1$ (III) CB8. (d) Cyanogen bromide patterns of, from left, normal, long-lived, and short-lived EDS IV.

(e) CM cellulose chromatography of cyanogen bromide cleaved EDS IV whole skin (note little or no type III peptides). (f) Pattern of normal whole skin for comparison.
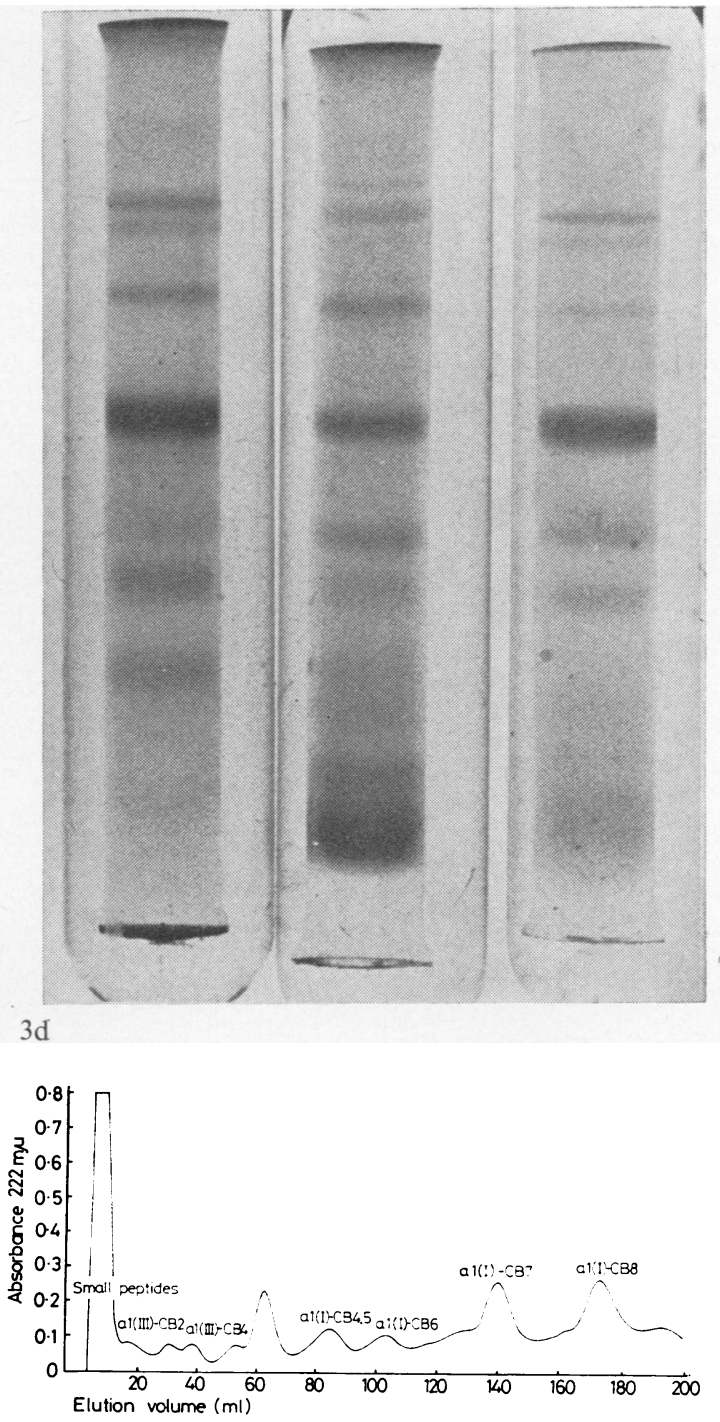

$3 e$

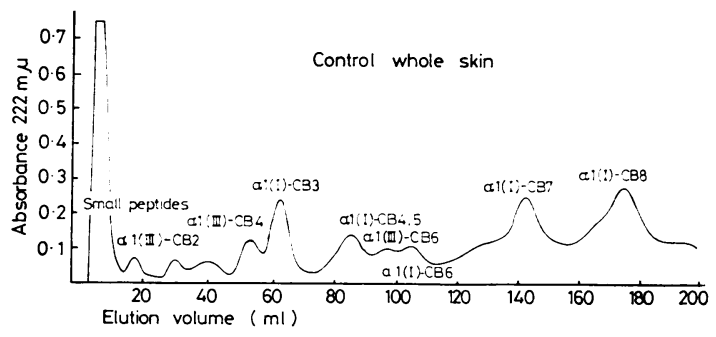




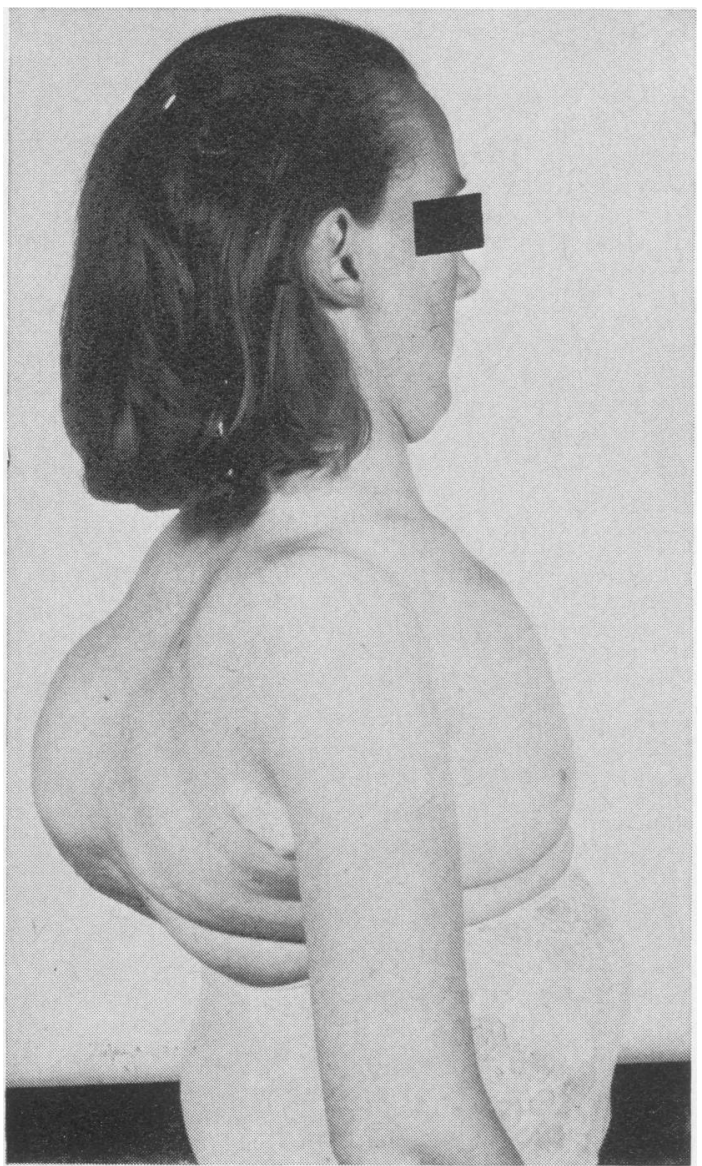

Fig. 4 Gross kyphoscoliosis in patient with EDS type VI.

located lens, and vascular problems are typical of the Marfan syndrome (Fig. 7). Classical (McKusick, 1972), heavy (McKusick, 1976), and loose-jointed (Marfanoid) (Walker et al., 1969) variants of the Marfan syndrome have been described. The first two are inherited as autosomal dominant characteristics, the latter as an autosomal recessive. We have recently seen a family with the typical Marfan syndrome but probable autosomal recessive inheritance; Fried and Krakowsky (1977) have reported a similar family. Dislocated lenses are typical of the classical variant, less common in the heavy, and absent in the Marfanoid type. Aortic rupture complicates all, especially the heavy variety. Idiopathic autosomal dominant aortic rupture is probably another variant of the syndrome. Specific biochemical defects wait identification. Homo- cystinuria was separated from the Marfan syndrome when the amino-aciduria of the former was identified. Two types, vitamin B6 responders and nonresponders, occur (Kang et al., 1970).

\section{PSEUDOXANTHOMA ELASTICUM (PXE)}

Two autosomal dominant (Pope, 1974a) and two autosomal recessive types (Pope, 1974b) of PXE have been described. Some or all could be molecular abnormalities of collagen. Many of the clinical features of inherited connective tissue disorders are detected, including hyperextensible skin, high arched palate, loose joints, blue sclerae, and skeletal deformities. Alterations in collagen ratios and patterns await identification.

\section{INHERITED ABNORMALITIES OF CARTILAGE}

Numerous clinical defects having in common dwarfism and degeneration or dislocation of large joints with various associated bony abnormalities are well recognised. The disorders include achondroplasia, pseudoachondroplasia, hypochondroplasia, and thanatophoric dwarfism. There are reviews by McKusick (1972), Spranger and Langer (1970), and Maroteaux and Lamy (1965). Evidence is beginning to accumulate that cartilage collagen may be affected in some of these syndromes (Byers et al., 1978; Holbrook et al., 1977). Horton et al. (1977) have preliminary evidence that abnormal cartilage collagens are produced by cultured chondrocytes from thanatophoric dwarfes and recognise three subtypes. Sewell et al.(1977), on the other hand, suggest that the glycosaminoglycans and not collagen are at fault.

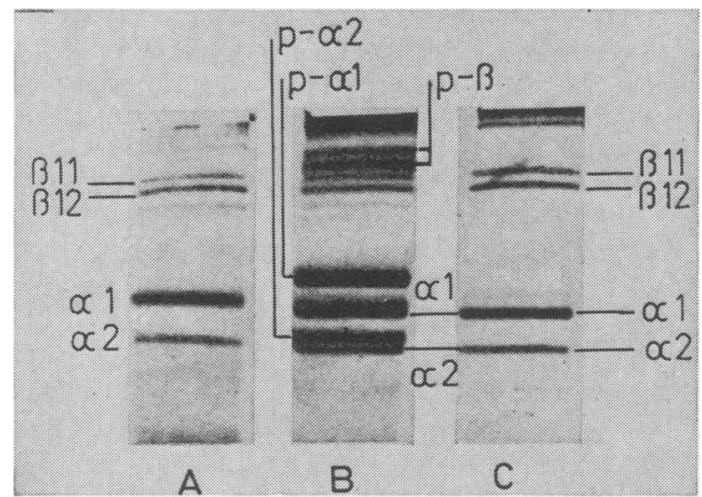

Fig. 5 Polyacrylamide electrophoresis of, from left, (a) normal skin collagen chains, (b) dermatosparaxic calf skin, (c) dermatosparaxic skin treated with procollagen peptidase. With kind permission of $\mathrm{Dr} A$. Bailey and European Journal of Biochemistry. 

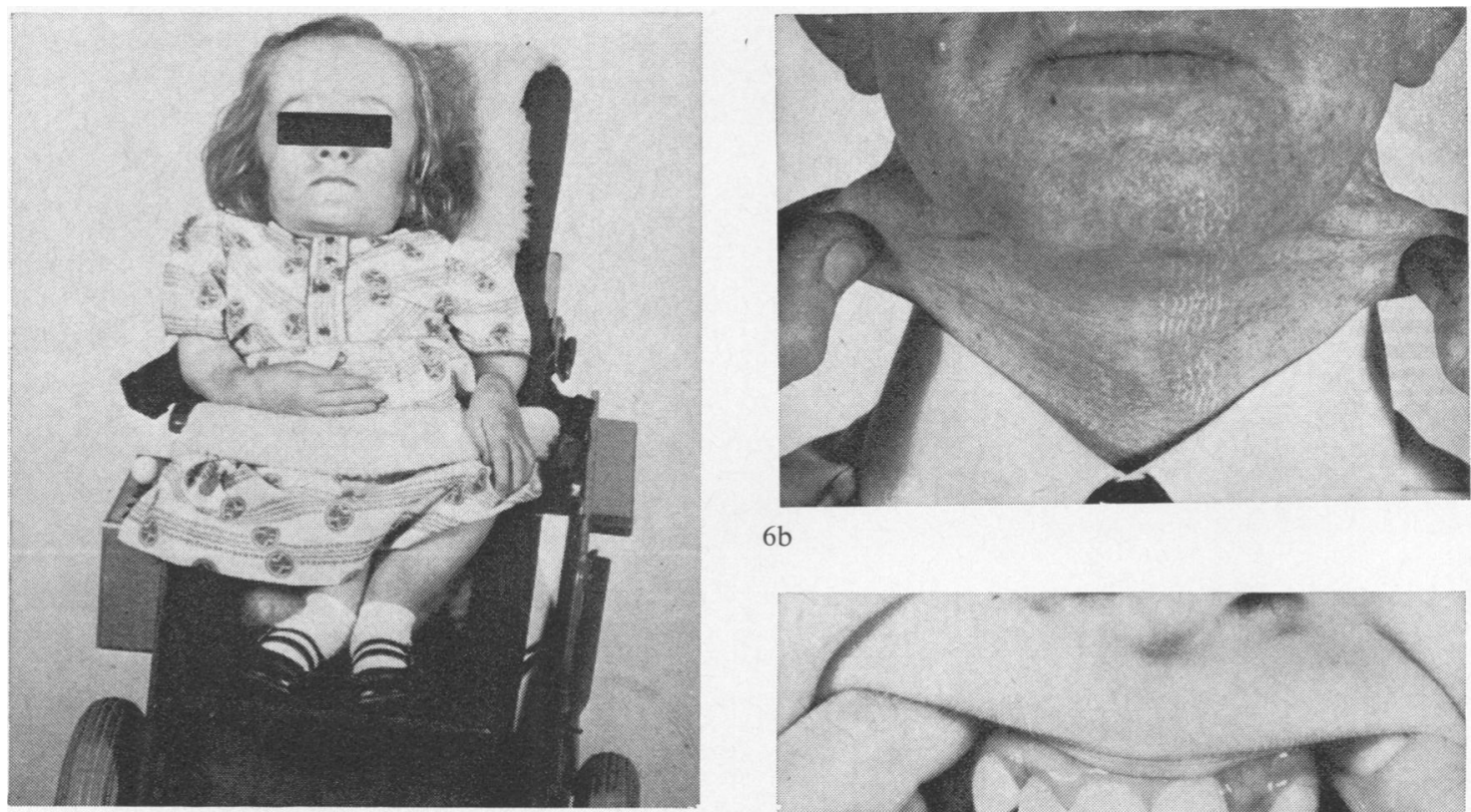

$6 b$

$6 a$

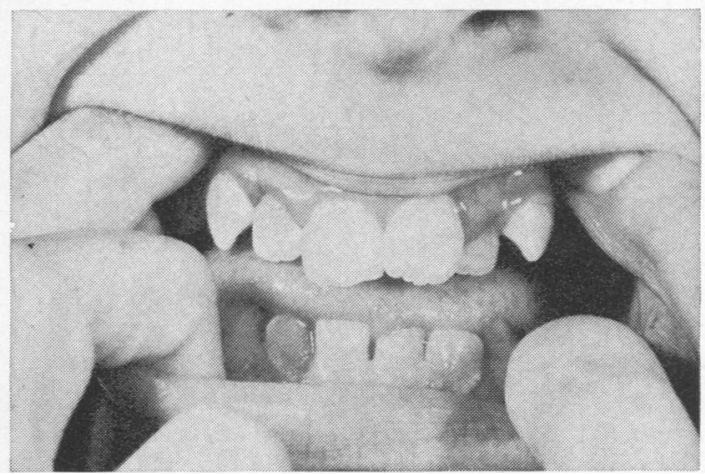

Fig. 6 (a) Patient with severely disabling osteogenesis imperfecta. (b) Presumed heterozygous parent of (a) showing abnormally extensible neck skin. (c) Partial dentinogenesis imperfecta in patient with osteogenesis imperfecta.

\section{Possible inherited defects of connective tissue}

\section{NEUROFIBROMATOSIS}

Neurofibromatosis may be heterogeneous. Some patients have clinical features reminiscent of inherited connective tissue defects (with extensible joints and skin, blue sclerae, and skeletal abnormalities). The perineurium contains type I and III collagens and cultured neurofibroma cells produce type I collagen (Penttinen et al, 1977). Further studies are needed.

\section{PROGERIA AND WERNER'S SYNDROME}

Cutaneous atrophy, premature vascular disease, and osteoporosis suggest a possible inherited collagen defect (Fig. 8). Clinical resemblances between progeria and acrogeria indicate that collagen synthesis or maturation may be faulty in the former. The latter has a specific deficiency of type III collagen.

\section{GENERAL DISORDERS OF COLLAGEN PRODUCTION}

These disorders, which are more fully discussed on other pages, include cirrhosis of the liver, pulmonary fibrosis, atheroma, keloid scarring, and systemic sclerosis. All have in common excessive deposition of collagen. One or more could follow the overproduction of collagen caused by unidentified stimulating factors. Collagen stimulators could be distributed in serum or tissue or liberated by cells such as lymphocytes or macrophages (Allison et al., 1977). McGee has described a collagen stimulator contained by cirrhotic livers (McGee et al., 1973; J. O'D. McGee and A. Fallon (McGee and Fallon, 1978) at p. 150).

Other pertinent problems that may reflect defects in the inheritance of connective tissue include 

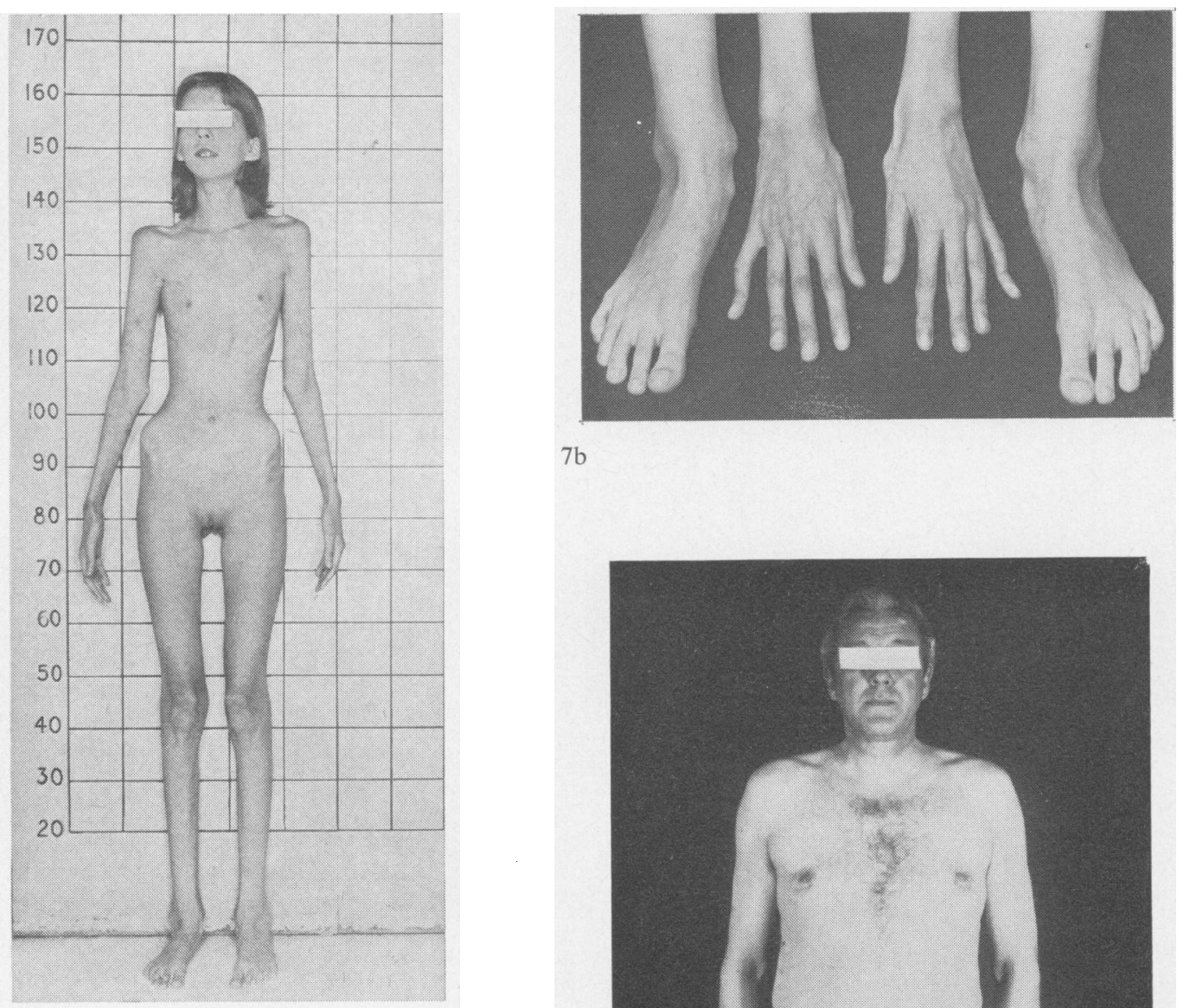

$7 \mathrm{~b}$

$7 a$

Fig. 7 (a) Asthenic Marfan variant. (b) Typical arachnodactyly. (c) Heavy Marfan variant.

susceptibility to varicose veins, herniae, and cerebral or other aneurysms. Although these characteristics are often graded, specific genetic susceptibility should be seriously considered in the explanation of some cases. The investigation of this inheritance is amenable to the analytical techniques outlined above.

\section{References}

Allison, A. C., Clark, I. A., and Davies, P. (1977). Cellular interactions in fibrogenesis. Annals of the Rheumatic Diseases, 36, Supplement 2, 8-13.

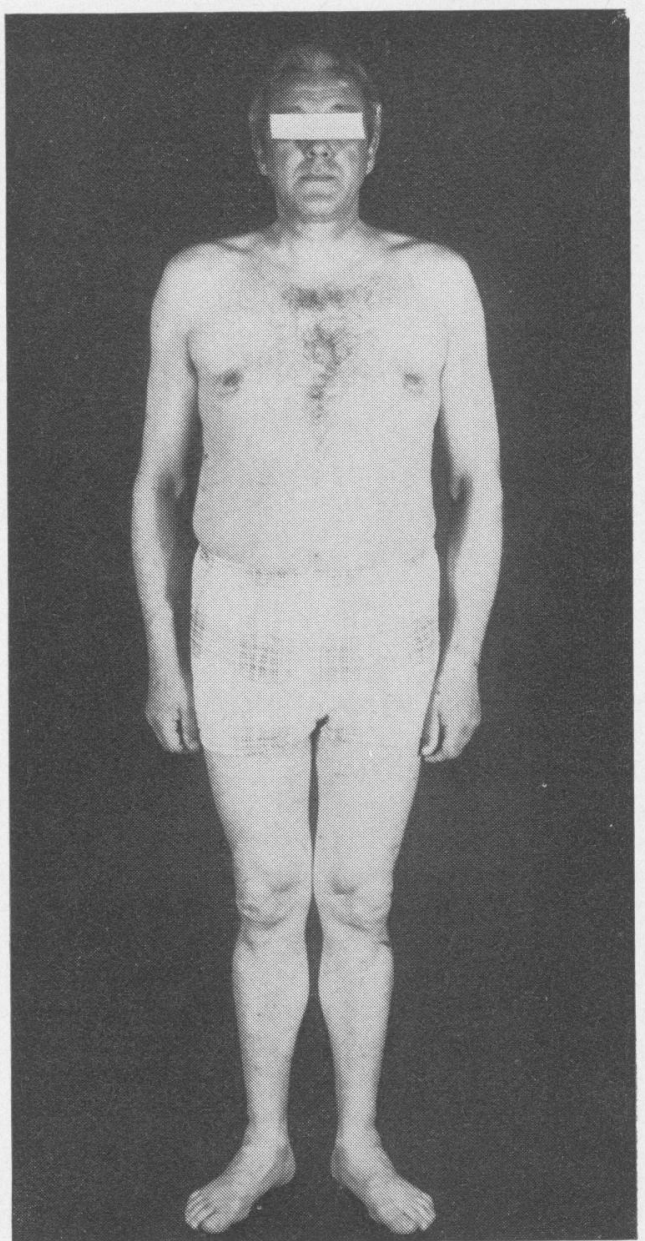

Fig. $7 c$ 


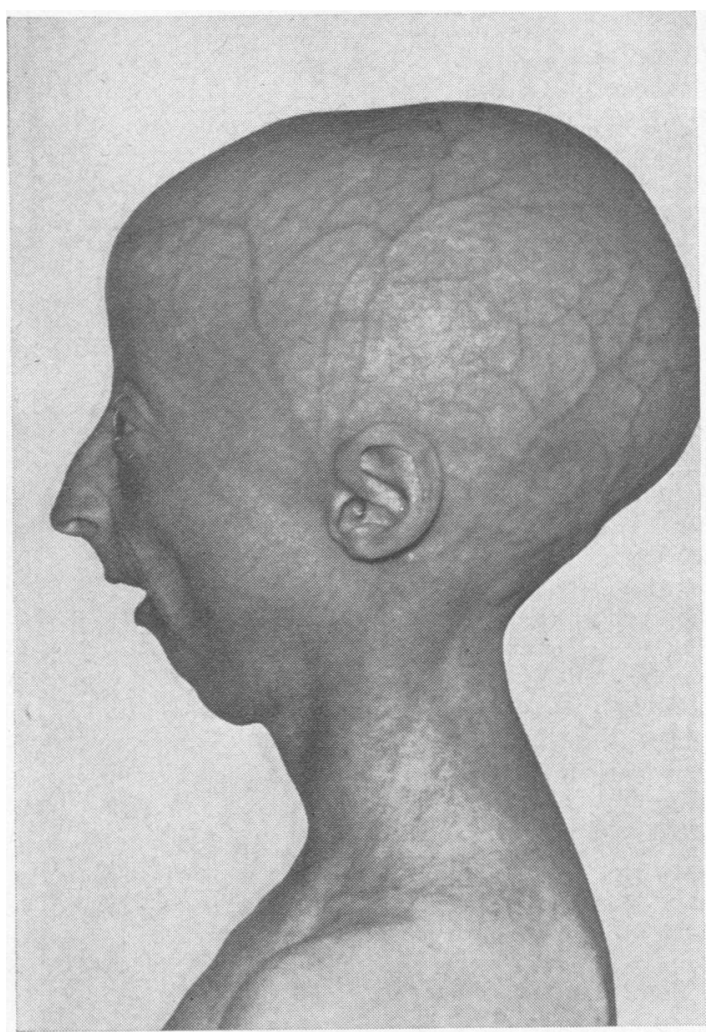

Fig. 8 Facies of patient with progeria.

Bailey, A. J. (1978). Collagen and elastin fibres. Journal of Clinical Pathology, 31, Supplement (Royal College of Pathologists) 12, 49-58.

Barabas, A. P. (1967). Heterogeneity of the EhlersDanlos syndrome: description of three clinical types and a hypothesis to explain the basic defect(s). British Medical Journal, 2, 612-613.

Bazex, A., and Dupré, A. (1955). "Acrogeria" (type Gottron): place de "l'acrogeria" dans le cadre des atrophies cutanees congenitates. Annals de Dermatologie et de Syphiligraphie, 82, 604-625.

Beighton, P. (1970). The Ehlers-Danlos Syndrome. Heinemann, London.

Benz, E. J., and Nathan, D. G. (1975). Applying molecular genetics to a human disease. Nature (London), 256, 163-164.

Byers, P. H., Holbrook, K. A., Hall, J. G., Bornstein, P., and Chandler, J. W. (1978). A new variety of spondyloepiphyseal dysplasia characterized by punctate corneal dystrophy and abnormal dermal collagen fibrils. Human Genetics, 40, 157-169.

DiFerrante, N., Leachman, R. D., Angelini, P., Dunnell, P. V., Francis, G., and Almazan, A. (1975). Lysyl oxidase deficiency in Ehlers-Danlos syndrome type V. Connective Tissue Research, 3, 49-53.
Ehlers, E. (1901). Cutis Laxa, Neigung zu Haemorrhagien in der Haut, Lockerung mehrere Artikulationen. Dermatologische Zeitschrift, 8, 173-174.

Fried, K., and Krakowsky, D. (1977). Probable autosomal recessive Marfan syndrome. Journal of Medical Genetics, 14, 359-361.

Gottron, H. (1941). Familiäre Akrogerie. Archiv für Dermatologie und Syphilis, 181, 571-583.

Helle, O., and Ness, N. N. (1972). A hereditary skin defect in sheep. Acta Veterinaria Scandinavica, 13, 443-445.

Holbrook, K. A., Byers, P. H., Bornstein, P., and Hall, J. G. (1977). Abnormal dermal collagen in a form of spondyloephipyseal dysplasia (Abstract). Journal of Investigative Dermatology, 68, 234.

Horton, W. A., Rimoin, D. L., Hollister, D. W., and Lachman, R. S. (1977). Further heterogeneity in lethal neonatal short-limbed dwarfism. Pediatric Research, 11, 526 (Abstract).

Jackson, D. S. (1978). Collagens. Journal of Clinical Pathology, 31, Supplement (Royal College of Pathologists) 12, 44-48.

Johnson, S. A. M., and Falls, H. F. (1949). EhlersDanlos syndrome: clinical and genetic study. Archives of Dermatology and Syphilology 60, 82-105.

Kang, E. S. Byers, R. K., and Gerald, P. S. (1970). Homocystinuria: response to pyridoxine. Neurology, 20, 503-507.

Lenaers, A., Ansay, M., Nusgens, B. V., and Lapière, C. M. (1971). Collagen made of extended $\alpha$-chains, procollagen, in genetically-defective dermatosparaxic calves. European Journal of Biochemistry, 23, 533-543.

Levin, L. S., Salinas, C. F., and Jorgenson, R. J. (1978). Classification of osteogenesis imperfecta by dental characteristics. Lancet, 1, 332-333.

Lichtenstein, J. R., Martin, G. R., Kohn, L. D., Byers, P. H., and McKusick, V. A. (1974). Defect in conversion of procollagen to collagen in a form of Ehlers-Danlos syndrome. Science, 182, 298-300.

McGee, J. O'D., and Fallon, A. (1978). Fibrosis of the liver-a collagen formative disease? Journal of Clinical Pathology, 31, Supplement (Royal College of Pathologists), 12, 150-157.

McGee, J. O'D. Hare, R. P., and Patrick, R. S. (1973). Stimulation of the collagen biosynthetic pathway by factors isolated from experimentally-injured liver. Nature (New Biology), 243, 121-123.

McKusick, V. A. (1959). Hereditary disorders of connective tissue. Bulletin of the New York Academy of Medicine, 35, 143-156.

McKusick, V. A. (1972). Heritable Disorders of Connective Tissue, 4th edition. Mosby, St Louis.

McKusick, V. A. (1975). Mendelian Inheritance in Man, 4th ed. Johns Hopkins University Press, Baltimore and London.

McKusick, V. A. (1976). Heritable disorders of connective tissue: new clinical and biochemical aspects. In 12th Symposium on Advanced Medicine, pp. 170-191. Pitman Medical, London.

Maroteaux, P., and Lamy, M. (1965). The malady of Toulouse-Lautrec. Journal of the American Medical Association, 191, 715-717.

Martin, G. R., and Steinemann, B. (1977). Personal 
communication

Penttinen, R. P., Lichtenstein, J. R., Martin, G. R., and McKusick, V. A. (1975). Abnormal collagen metabolism in cultured cells in osteogenesis imperfects. Proceedings of the National Academy Sciences of the United States of America, 72, 586-589.

Penttinen, R. P., Marttala, T., and Hollmén, T. (1977). Neurofibromatosis cells synthesize type I collagen (Abstract). Upsala Journal of Medical Sciences, 82, 149.

Pinnell, S. R., Krane, S. M., Kenzora, J., and Glimcher, M. J. (1972). A heritable disorder of connective tissue: hydroxylysine-deficient collagen disease. New England Journal of Medicine, 286, 1013-1020.

Pope, F. M. (1974a). Autosomal dominant pseudoxanthomo elasticum. Journal of Medical Genetics, 11, 152-157.

Pope, F. M. (1974b). Two types of autosomal recessive pseudoxanthoma elasticum. Archives of Dermatology, 110, 209-212.

Pope, F. M. (1976). Collagen and osteogenesis imperfecta (Letter). Lancet, 1, 1024.

Pope, F. M. (1977). Ehlers-Danlos syndrome. Proceedings of Royal Society of Medicine, 70, 895-896.

Pope, F. M., Martin, G. R., Lichtenstein, J. R., Penttinen, R., Gerson, B., Rowe, D. W., and McKusick, V. A. (1975). Patients with Ehlers-Danlos syndrome type IV lack type III collagen. Proceedings of the National Academy of Sciences of the United States of America, 72, 1314-1316.

Pope, F. M., Martin, G. R., and McKusick, V. A. (1977). Inheritance of Ehlers-Danlos type IV syndrome. Journal of Medical Genetics, 14, 200-204.
Rook, A., Wilkinson, D. S., and Ebling, F. J. G., Eds. (1972). Textbook of Dermatology, 2nd edition. Blackwell, Oxford.

Rowe, D. W., McGoodwin, E. B., Martin, G. R., Sussman, M. D., Grahn, D., Faris, B., and Franzblau, C. (1974). A sex-linked defect in the cross-linking of collagen and elastin associated with the mottled locus in mice. Journal of Experimental Medicine, 139, 180-192.

Sewell, A. C., Spranger, J. W., and Pennock, C. A. (1977). Epiphyseal cartilage chemistry in thanatophoric dwarfism (Letter). Lancet, 1, 854.

Spranger, J. W., and Langer, L. O., Jr. (1970). Spondyloepiphyseal dysplasia congenita. Radiology, 94, 313-322.

Steinmann, B., Abe, S., Martin, G. R., and McKusick, V. A. (1977). Collagen disorders. Upsala Journal of Medical Sciences, 82, 80.

Sussman, M. D., Lichtenstein, J. R., Nigra, T. P., Martin, G. R., and McKusick, V. A. (1974). Hydroxylysine-deficient skin collagen in a patient with a form of the Ehlers-Danlos syndrome. Journal of Bone and Joint Surgery, 56A, 1228-1234.

Sykes, B., Francis, M. J. O., and Smith, R. (1977). Altered relation of two collagen types in osteogenesis imperfecta. New England Journal of Medicine, 296, 1200-1203.

Walker, B. A., Beighton, P. H., and Murdoch, J. L. (1969). The Marfanoid hypermobility syndrome. Annals of Internal Medicine, 71, 349-352.

Williamson, B. (1977). Unravelling the genetics of a blood disease. New Scientist, 75, 406-408. 